\title{
"O Brasil que eu quero": inovação social, democracia e televisão no contexto brasileiro
}

\author{
Juliana Matte ${ }^{1}$ \\ Eduardo Luiz Cardoso ${ }^{2}$ \\ Fabio Teodoro Tolfo Ribas ${ }^{3}$ \\ Cassiane Chais ${ }^{4}$ \\ Pelayo Munhoz Olea ${ }^{5}$
}

\begin{abstract}
Resumo
Este estudo teve como objetivo descobrir o que a população brasileira deseja para o seu futuro, por meio de uma análise de conteúdo a partir dos vídeos apresentados no quadro "O Brasil que Eu Quero" da emissora Globo de televisão. Os resultados da pesquisa mostram que o que os brasileiros querem para o futuro do Brasil é um país que invista em educação, saúde, segurança pública e moradias dignas. Os brasileiros esperam o dinheiro público, arrecadado pelo governo através do regime tributário nacional, seja investido em benefícios sociais, infraestrutura, educação e saúde, que tragam melhorias na qualidade de vida da população como um todo. Os brasileiros desejam para o futuro, que se tenha respeito com o dinheiro e patrimônio público e que os governantes busquem o bem comum ao invés de seus interesses particulares. Ao longo da pesquisa percebeu-se o sentimento de indignação da população brasileira diante dos casos de corrupção que assolam o país em todas as esferas. Além de pedir pelos seus direitos constitucionais, a população brasileira almeja o fim da corrupção no país, para o Brasil volte a ser um país respeitado no cenário internacional e atraia investimentos que possam contribuir para o seu desenvolvimento.
\end{abstract}

Palavras-chave: Mídia Televisiva. Inovação Social. Democracia. Brasil. Direitos Constitucionais.

\section{"The Brazil I want": social innovation, democracy, and television in the brazilian context}

\begin{abstract}
This study aimed to find out what the Brazilian population wants for their future, through a content analysis based on the videos presented in the "O Brasil que Eu Quero" chart of the Globo television station. The survey results show that what Brazilians want for the future of Brazil is a country that invests in education, health, public security and decent housing. Brazilians expect public money, collected by the government through the national tax regime, to be invested in social benefits, infrastructure, education and health, which bring improvements in the quality of life of the population as a whole. Brazilians wish for the future that respect is given to money and public assets and that government officials seek the common good instead of their private interests. Throughout the research, the feeling of indignation of the Brazilian population towards the corruption cases that plague the country in all spheres was perceived. In addition to claiming their constitutional rights, the Brazilian population aims to end corruption in the country, so that Brazil will once again be a respected country on the international stage and attract investments that can contribute to its development.
\end{abstract}

Keywords: Television Media. Social Innovation. Democracy. Brazil. Constitutional Rights.

${ }^{1}$ Doutoranda em Administração no Programa de Pós-Graduação em Administração da Universidade de Caxias do Sul (UCS). Bolsista FAPERGS/CAPES. http://orcid.org/0000-0003-0945-2479 E-mail: ju.cxs1@gmail.com

2 Doutorando em Administração na Universidade de Caxias do Sul (UCS). Professor da Universidade de Caxias do Sul (UCS). E-mail: elcardo1@ucs.br

${ }^{3}$ Doutorando em Administração na Universidade de Caxias do Sul (UCS). Professor no Centro Universitário da Serra Gaúcha (FSG). E-mail: fabio.ribas@fsg.edu.br

${ }^{4}$ Doutora em Administração (UCS). Coordenadora do Parque de Ciência Tecnologia e Inovação da Universidade de Caxias do Sul (TecnoUCS). http://orcid.org/0000-0002-1922-9273 E-mail: cassichais@gmail.com

${ }^{5}$ Pós-Doutor em Gestão Ambiental (Universidad de Extremadura, Espanha). Doutor em Administração e Direção de Empresas (Universitat Politècnica de Catalunya, Espanha). Professor na Universidade Federal do Rio Grande (FURG). http://orcid.org/0000-0003-2183-8112 E-mail: pelayo.olea@gmail.com 


\section{Introdução}

A inovação social se tornou, recentemente, uma preocupação consciente de discussão política, apesar de ocorrer na vida cotidiana, nos movimentos sociais e em toda a sociedade há anos (MURRAY; MULGAN; COULIER-GRICE, 2008). Conforme Bignetti (2011) e Dainiene e Dagiliene (2015), desde os anos 2000, o interesse por inovações sociais está em ascensão, em função de demandas para o desenvolvimento de novas abordagens que colaborem na revisão e análise dos desafios sociais. Pode-se destacar também que o aumento do interesse pela inovação social foi fruto da contínua e crescente necessidade dos poderes públicos, organizações da sociedade civil, empresas privadas e indivíduos, buscarem respostas aos riscos sociais, com novas abordagens, mais eficazes e utilizando recursos reduzidos (BEPA, 2014).

Outro fator de influência no surgimento de inovações sociais é o déficit do Estado quanto ao atendimento de demandas sociais (MOULAERT et al., 2013). Nos últimos anos, a inovação social tornou-se cada vez mais influente, tanto na educação quanto na política, alicerçando as relações de confiança baseadas na comunidade, em grupos de reflexão, em práticas de gestão de empresas e nos programas de financiamento do governo, levando a uma ampla gama de projetos e redes internacionais que promovem novas formas de atuação, com base nas relações sociais e experiências de quem necessita dessas ações (MOULAERT et al., 2013).

Neste sentido, o sistema democrático, segundo Schumpeter (1961), é o modelo de arranjo institucional para se chegar a certas decisões políticas que realizam o bem comum, sendo que a decisão é tomada pelo povo, por meio da eleição de indivíduos que são escolhidos para cumprir a vontade do povo. Durante os últimos anos da década de 1960, a palavra "participação" tornou-se parte do vocabulário político popular. Isso ocorreu sob o impulso de demandas, notadamente de estudantes, por novas áreas de participação a serem abertas (LYON, 1971). Da democracia espera-se que produza melhorias no desempenho do estado, altere padrões de gastos do governo para alocar recursos de maneira eficiente e justa e, que melhore a qualidade da vida pública (TOUCHTON; WAMPLER, 2014).

No Brasil, o papel que a televisão cumpre como mídia dominante decorre da possibilidade de construir a realidade por meio da representação que faz, em seus telejornais, da própria política e dos políticos (FERNANDES, 2013). Essa discussão assume relevância no contexto brasileiro, já que parte significativa da informação que o telespectador recebe vem da televisão, que funciona como única via de acesso às notícias e ao entretenimento para grande parte da 
população. As informações chegam ao telespectador principalmente pelos telejornais, de grande abrangência, considerados por isso, um dos mais importantes meios de informação (FERNANDES, 2013). A mídia televisiva é o meio de comunicação de maior repercussão e alcance entre a população brasileira, como apontou uma pesquisa de hábitos de audiência realizada pela SECOM (Secretaria de Comunicação Visual da Presidência da República) no ano de 2010, 94,2\% da população brasileira utiliza a televisão como fonte de informação e entretenimento.

A Rede Globo é uma rede de televisão comercial aberta brasileira com sede no Rio de Janeiro que possui uma audiência de mais de 200 milhões de pessoas diariamente, tanto no Brasil como no exterior. A emissora é a segunda maior rede de televisão comercial do mundo, atrás apenas da norte-americana American Broadcasting Company $(A B C)$ e uma das maiores produtoras de telenovelas. A emissora alcança $98,56 \%$ do território brasileiro, atendendo a 5.490 municípios e cerca de $99,55 \%$ do total da população brasileira. A empresa é parte do Grupo Globo, um dos maiores conglomerados de mídia do mundo, com cinco emissoras próprias e 118 emissoras afiliadas, além da transmissão no exterior pela TV Globo Internacional e do serviço mediante assinatura no país (REDE GLOBO, 2017).

No ano eleitoral de 2006, o Jornal Nacional, telejornal noturno da emissora, exibiu uma série intitulada Caravana JN. O projeto percorreu as cinco regiões do Brasil, apresentou 52 reportagens, produzidas de 31 de julho a 29 de setembro de 2006, a bordo de um ônibus, no qual o apresentador e sua equipe buscaram descobrir quais seriam os desejos dos brasileiros para o próximo presidente. Em 2018, ano eleitoral, novamente a emissora apresentou uma proposta de inovação social direcionada a toda a população brasileira buscando responder ao seguinte questionamento: "Que Brasil você quer para o futuro?" Toda a população brasileira foi convidada a enviar um vídeo para a emissora, respondendo a esse questionamento a fim de que o mesmo fosse exibido em um de seus telejornais, regionais ou nacionais. Diante do exposto, este estudo teve como objetivo descobrir o que a população brasileira deseja para o seu futuro, por meio de uma análise de conteúdo a partir dos vídeos apresentados.

Com a proposta deste quadro, a Rede Globo estaria proporcionando um espaço para a expressão democrática do brasileiro, por ser a emissora de maior abrangência nacional, contemplando seu papel social no contexto democrático de "dar voz ao povo" (FERNANDES, 2013). Portanto, a partir deste quadro da emissora, este estudo teve como objetivo descobrir o que a população brasileira deseja para o seu futuro, por meio de uma análise de conteúdo a partir dos vídeos apresentados no quadro “O Brasil que Eu Quero" da emissora Globo de televisão. Para isso, este artigo está estruturado, além desta etapa introdutória, em referencial 
teórico apresentando os conceitos de inovação social e democracia, método de pesquisa, resultados encontrados e considerações finais.

\section{Inovação social e democracia no Brasil}

A inovação social é um tema que tem gerado recentes debates em todo o mundo, pois as estruturas existentes e as políticas estabelecidas não apresentam soluções na eliminação dos prementes problemas dos tempos atuais, como as desigualdades sociais, a sustentabilidade e a inclusão social (MURRAY; MULGAN; COULIER-GRICE, 2008). Em resposta a uma situação social que visa ao bem-estar dos indivíduos e da coletividade por meio do atendimento a necessidades como saúde, educação, trabalho, lazer, transporte e turismo, a inovação social surge como uma forma de se buscar alternativas viáveis para o futuro da sociedade (BIGNETTI, 2011). A inovação social é resultado do conhecimento aplicado a necessidades sociais, por meio da participação e da cooperação dos atores envolvidos, gerando soluções novas e duradouras para grupos sociais, comunidades ou para a sociedade em geral (BIGNETTI, 2011).

Para Neumeier (2012), a inovação social não é apenas uma melhoria tangível, mas sim mudanças de atitude, comportamento e percepção, que resultam em uma nova forma de ação colaborativa, que leva à melhoria da qualidade de vida. Conforme Murray, Mulgan e CoulierGrice (2008), a inovação social ocorre por meio de produtos, serviços e modelos que simultaneamente satisfazem necessidades sociais e criam novas relações ou colaborações sociais.

A inovação social remete aos processos de mobilização, participação e ao resultado de ações que conduzem a melhorias nas relações sociais, estruturas de governo e empoderamento coletivo (MOULAERT et al., 2013). A inovação social pode ser considerada um processo, sendo que sua implementação é iniciada por diferentes atores sociais (VAILLANCOURT, 2017), resulta em melhoria da qualidade de vida (POL; VILLE, 2009) e estimula a coparticipação da sociedade civil em resposta às demandas sociais em áreas como educação, saúde e relações sociais (HARAYAMA; NITTA, 2011; MOULAERT et al., 2013; VAILLANCOURT, 2017).

A busca por novas respostas para os problemas sociais, através da identificação e oferta de novos serviços que melhorem a qualidade de vida de indivíduos e comunidades, a identificação e implementação de novos processos de integração no mercado de trabalho, novas competências, novos empregos e novas formas de participação são os objetivos da inovação social (OECD, 2017). Nesse sentido, a complexidade das inovações sociais decorre de sua 
abrangência, uma vez que os desafios sociais estão relacionados com as mudanças demográficas, as alterações climáticas, a pobreza, o emprego, os cuidados de saúde e com a educação, caracterizando-se de forma multidimensional (HARAYAMA; NITTA, 2011).

Portanto, haja visto que a inovação social é realizada por meio da participação e da cooperação dos atores envolvidos (BIGNETTI, 2011), a democracia se mostra como uma forma de governo que propicia esse tipo de participação da população com as ações do governo. Especificamente, a inovação social deve seguir a democracia deliberativa, na qual o acesso às informações, a formação crítica e o protagonismo comunitário sejam subsídios para a intervenção no campo social" (LACERDA; FERRARINI, 2013, p. 10).

$\mathrm{Na}$ Teoria da Democracia confluem três tradições do pensamento político: a Teoria Clássica ou Aristotélica, que demonstra como seria o modelo de governo do povo, diferente da monarquia ou da aristocracia; a Democracia Medieval, que tem origem romana, é apoiada na soberania popular e pode se originar de forma descendente, onde o poder deriva do povo se tornando representativo ou de uma forma ascendente, onde o poder deriva do príncipe para o povo por delegação e; a Teoria Democrática Moderna, que nasce no Estado Moderno e está associada aos ideais republicanos, onde um governo genuinamente popular é chamado, em vez democracia ou república (BOBBIO; MATTEUCCI; MASQUINO, 2008).

A democracia moderna caracteriza-se pela valorização crescente do conceito de homem e sua participação na política. Este novo momento do estado surge, juntamente com os direitos humanos, e é reconhecido como a era dos direitos, que passam a ser buscados em sentido universal (ABBAGNANO, 2017). Segundo Abbagnano (2017), esta democracia passa a ser considerada a política fundada nos direitos humanos, primeiramente sendo reconhecidos os direitos civis, depois os políticos, a seguir os direitos sociais e, por fim, os direitos coletivos através de estruturas supranacionais. A democracia pura é aquela assim chamada principalmente em função da igualdade que prevalece nela: que os pobres não serão menosprezados, nem os ricos supervalorizados; nem que o poder supremo se aloje a ambos, mas que ambos o compartilhem (DAHL, 2006).

Segundo Pogrebinschi e Samuels (2014), a definição de democracia proposta por Schumpeter a reduz a um procedimento no qual as elites competem pelos votos dos cidadãos, sendo que esta massa eleitoral é incapaz de agir. Pogrebinschi e Samuels (2014) definem a democracia em termos processuais, como um arranjo institucional no qual os líderes adquirem controle sobre o governo por meio de um processo eleitoral competitivo. A democracia moderna é necessariamente representativa, porque as políticas modernas não permitem a participação 
em massa no processo de governo (POGREBINSCHI; SAMUELS, 2014). Um exemplo é a democracia no Brasil, contexto desta pesquisa.

Em 1992, com o impeachment do presidente Fernando Collor de Mello, o Brasil testemunhou o fato de que a sua democracia adquiriu uma estabilidade considerável. Pela primeira vez na história do país, uma grave crise governamental foi resolvida sem recurso a meios extraconstitucionais (WEYLAND, 1993).

Em 2013, o país apresentou uma forte instabilidade política, e pela primeira vez, após o impeachment de 1992, o povo ocupou as ruas sem a presença de partidos políticos ou organizações da sociedade civil, em oposição ao sistema político daquele ano. Em março de 2014, o esquema de lavagem e desvio de dinheiro da Petrobras foi exposto com as primeiras detenções realizadas no âmbito da Operação Lava Jato (NUNES; MELO, 2017). O início das investigações representou 28 denúncias do Ministério Público Federal contra 128 pessoas (BENITES, 2015).

Ao mesmo tempo, houve protestos contra a realização da Copa do Mundo - algo antes impensável na "nação do futebol" (DA MATTA, 2004) - que se concentrou nas demandas das pessoas por maiores gastos com saúde, educação e transporte público, em detrimento dos US\$ 3,6 bilhões em dinheiro dos contribuintes gastos na construção de estádios. Assim, a corrupção desenfreada e a ineficiência organizacional afetaram negativamente a preparação do país para o evento (MITRA, 2015).

Em abril de 2016, foi aprovado pela Câmara dos Deputados o impeachment da presidente Dilma Rousseff (2010-2016), perdendo o mandato de Presidente da República em 31 de agosto de 2016, quando assumiu o vice-presidente Michel Temer até 2018. Em 5 de abril de 2018, seis meses antes das eleições gerais, o juiz federal Sérgio Moro, futuro Ministro da Justiça do novo governo eleito nesse ano, decretou a prisão do ex-presidente Luiz Inácio da Silva (presidente da república de 2003 a 2010), quando novamente era candidato a presidente da república pelo Partido dos Trabalhadores (PT), sendo este preso nos dias seguintes pela Polícia Federal. É nesse cenário que esta pesquisa foi realizada, com a intenção de descobrir o que a população brasileira desejava para o seu futuro.

\section{Método}

A pesquisa realizada é de natureza qualitativa, de caráter exploratório (DENZIN; LINCON, 2008), realizada por meio de uma análise de conteúdo (BARDIN, 2011), utilizando dados secundários (vídeos do quadro "O Brasil que eu quero"), com posterior análise descritiva dos 
indicadores (HAIR Jr. et al., 2009). Para a caracterização da população e amostragem, inicialmente coletou-se informações no site do Instituto Brasileiro de Geografia e Estatística (IBGE, 2010), onde foram encontradas informações quanto à população por Estado brasileiro e número de municípios por Estado.

Através da análise ponderada, obteve-se a amostragem de vídeos a serem analisados considerando os Estados com maior número de municípios e os Estados com maior contingente populacional. Para um total de 5.570 municípios, foi definida uma amostra de 2.034 vídeos, correspondendo a 2.034 municípios (36,51\% dos municípios brasileiros). Uma particularidade da amostra é o Distrito Federal, contemplado com um único vídeo para representar uma população de 3 milhões de habitantes. A coleta de vídeos teve início em 04 de março e foi finalizada em 16 de junho de 2018. A Tabela 1 apresenta a amostra por região, população e número de municípios.

Tabela 1 - Distribuição das cidades analisadas por região

\begin{tabular}{lccrr}
\hline Região & População & Municípios & \multicolumn{1}{c}{ Cidades Analisadas } \\
\hline Centro-Oeste & 15.875 .907 & 467 & 158 & $33,8 \%$ \\
Norte & 17.936 .201 & 450 & 185 & $41,1 \%$ \\
Nordeste & 57.254 .159 & 1.794 & 628 & $35 \%$ \\
Sul & 29.644 .948 & 1.191 & 372 & $31,2 \%$ \\
Sudeste & 86.949 .714 & 1.668 & 691 & $41,4 \%$ \\
\hline Total Geral & $\mathbf{2 0 7 . 6 6 0 . 9 2 9}$ & $\mathbf{5 . 5 7 0}$ & & \\
\hline
\end{tabular}

Fonte: Dados do IBGE (2010).

O quadro "O Brasil que eu quero" teve sua exibição iniciada no dia 04 de março de 2018, inserido nos telejornais da emissora Globo. Os vídeos também foram disponibilizados no site da emissora. Para o desenvolvimento da pesquisa, os vídeos foram captados no site da emissora através da página http://g1.globo.com/o-brasil-que-eu-quero/. Após a captação dos vídeos, os mesmos foram distribuídos para o grupo de pesquisa (sete pesquisadores) responsável pela transcrição dos vídeos com suporte do software Microsoft Excel 2013.

Ao longo da execução desta pesquisa, foram transcritos 2.034 vídeos integralmente, e, posteriormente, foi utilizado o software $N$ Vivo ${ }^{\circledR} 10$ para a categorização e organização das informações. Em um primeiro momento, foram definidas as categorias comuns (nós) no texto, para que fossem realizados os agrupamentos, levando em consideração os temas definidos. Neste estudo, as categorias identificadas a priori foram "cidadão" e "democracia" e como categorias a posteriori, "corrupção" e "justiça". A categoria "cidadão" se refere ao comportamento do brasileiro, como membro ativo da sociedade. Já "democracia" remete às falas de igualdade e de democracia evocadas pelos participantes, na perspectiva do governo, ou seja, o governo como provedor de igualdade. Para a categoria "corrupção", foi atribuído o 
conteúdo não somente relacionado a corrupção em si, mas também, os benefícios que os políticos obtêm por meio deste ato, desprivilegiando a sociedade. Por fim, a categoria "justiça" agrupa as informações relacionadas ao não cumprimento da legislação e injustiças, identificadas por grande parte dos participantes da pesquisa.

\section{4 “O Brasil que eu quero"}

A partir dos dados levantados com a transcrição dos vídeos do quadro "O Brasil que eu quero" foram realizadas as análises com o auxílio do software Nvivo 10. As análises iniciaram buscando descobrir o que o brasileiro quer para o futuro do Brasil como um todo. As principais demandas do povo brasileiro, diante deste questionamento, remetem à "educação", "saúde" e "corrupção na política", como pode ser observada na fala do participante de Trindade (PE): "É um país sem corrupção, com mais investimentos em saúde, educação e segurança pública" e pelo morador de Afonso Cláudio (ES): “É um Brasil com políticos decentes, que governem para o povo. Quero ver um Brasil que invista mais em educação. Somos o povo e só o povo pode mudar esta página que envergonha o nosso país".

Este posicionamento coaduna com Hoelscher (2015), que afirma que a corrupção política nos níveis locais continua a ser um problema considerável, pois vários órgãos do sistema público estão envolvidos com atos ilegais e isto continua moldando as decisões políticas, dificultando assim a possibilidade de admitir que o Brasil tenha consolidado plenamente suas instituições democráticas. A nuvem de palavras, ilustrada na Figura 1, evidencia as principais demandas dos participantes para o futuro do Brasil, como educação, combate à corrupção e saúde.

As análises continuam com a geração de clusters de palavras, conforme a Figura 2, podese verificar o resultado das ligações e recorrência de citações entre as palavras, elucidando o contexto em que essas expressões foram ditas. Entre os resultados verificou-se ocorrências vinculadas às palavras (i) cuidado com a natureza; (ii) respeito e saúde; (iii) educação e saúde e; (iv) impostos. Através da análise de cluster, a primeira relação mostra que uma das demandas e expectativas dos brasileiros relacionadas ao seu futuro é que a população brasileira dê atenção e cuide da natureza. O participante de Arauanã (GO) confirma essa informação: “Quero um Brasil que se preocupe mais com nossos rios e lagos para que nossos netos possam desfrutar dessa beleza", assim como o morador de Rorainópolis (RR): "É um futuro sem corrupção, com menos desmatamento e mais preservação da natureza". Da mesma forma, Cole, Elliott e Fredryksson 
Figura 1 - Nuvem de palavras com os desejos do brasileiro para o futuro do país

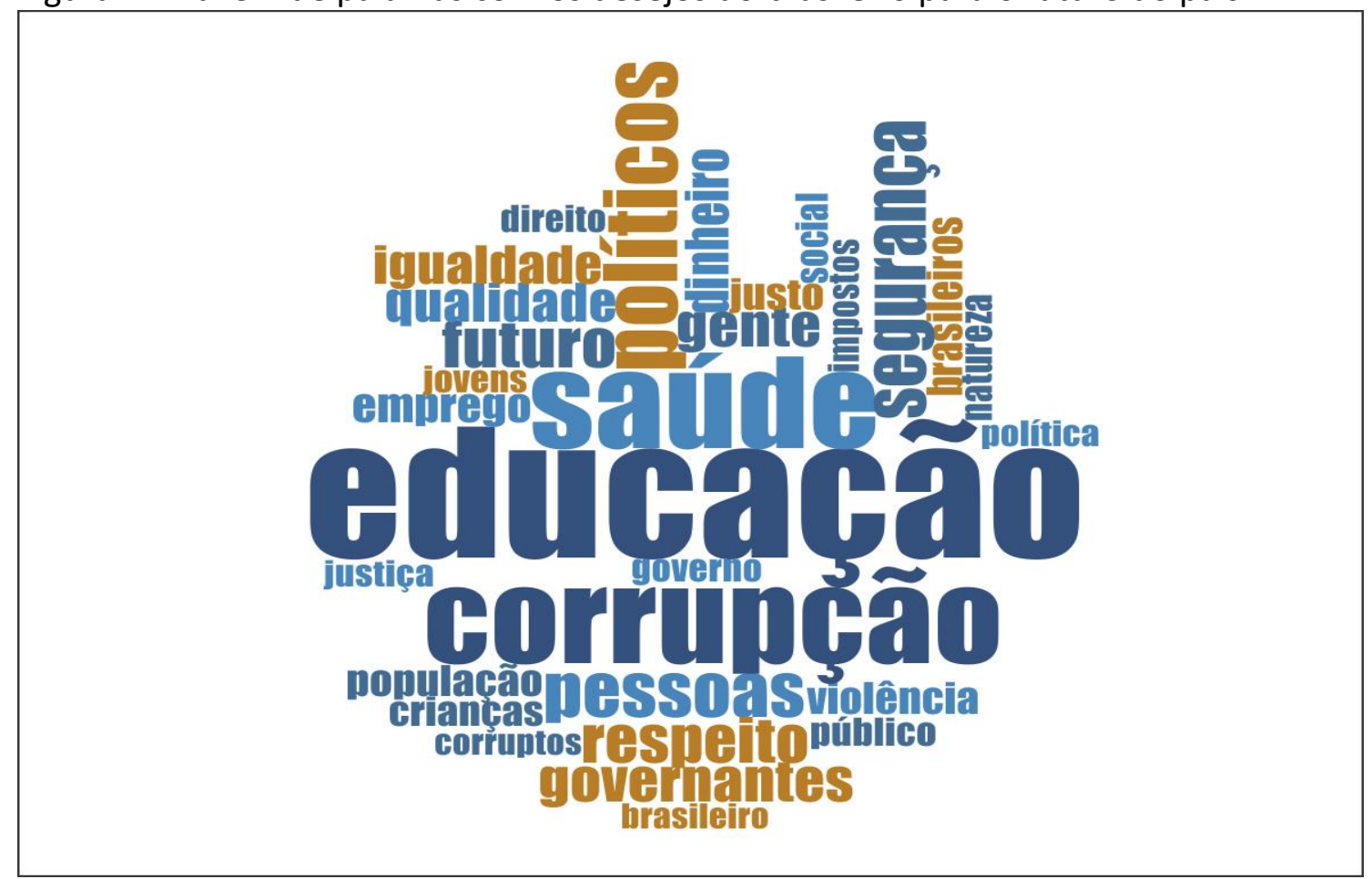

Fonte: Dados da pesquisa qualitativa (2018).

A segunda relação refere-se ao emprego, oriundo do respeito e da justiça, que deve ser proporcionado pelo governo ao povo brasileiro. A declaração do participante de São Gabriel (RS) reitera essa relação: "É um Brasil com mais respeito, mais emprego e menos preconceito", bem como do participante de Pomerode (SC): “Desejo um Brasil mais justo, com mais empregos, com mais seriedade, com mais projetos em prol do cidadão e não dos políticos com mala cheio de dinheiro". Essa crescente atenção à corrupção identificada nos resultados pode ajudar a reduzir a corrupção no futuro, pois podem ajudar a transmitir aos políticos a sensação de que a corrupção pode se tornar uma barreira às eleições (BALAN, 2014).

A terceira relação, apontada pelos resultados da pesquisa, sugere que a corrupção praticada pelos políticos brasileiros fere o acesso à educação e a saúde, direitos do cidadão, atingindo o jovem e seu futuro. O participante da cidade de Rio de Contas (BA) comentou a respeito: “É mais oportunidades para o jovem de baixa renda em questão de estudo e trabalho e também um país onde os políticos pensem mais no bem-estar da população do que do seu próprio enriquecimento a partir do dinheiro público". Esse resultado corrobora com WeitzShapiro e Winters (2017), que destacam que os cidadãos reagem negativamente a alegações de corrupção, pois a corrupção política viola fundamentalmente o contrato implícito no qual os 
políticos eleitos concordam em governar em nome dos cidadãos que os escolheram (ROSEACKERMAN; PALIFKA, 2016).

Outro fator que atinge ao futuro dos brasileiros é o fato de que os impostos pagos pela população não são revertidos em políticas que beneficiem as crianças, prejudicando o futuro do país. O morador de Catende (PE) citou um exemplo: "São estradas decentes na zona rural para que possa levar as crianças para a escola, de inverno a verão, porque quando chega o inverno, por causa da lama, as crianças ficam sem estudar por falta de transporte". Complementa o morador de Macuco (RJ) que reforçou: "Um país justo para todos nós, onde não haja tanta corrupção e também de direitos das nossas crianças e adolescentes que estão sendo violados".

A quarta relação do cluster se refere à má gestão do dinheiro público, que deixa de investido pelos governantes em prol do bem-estar da população, levando a um quadro de violência, como ilustrou o morador de Goianápolis (GO): “A violência contra a criança ou adolescente seja riscada em todas suas esferas, e que o dinheiro público seja usado de forma eficiente e eficaz". Além disso, o morador de Santa Quitéria do Maranhão (MA) complementa: "um Brasil com menos corrupção e menos violência, e principalmente com maior responsabilidade com o dinheiro público, esta obra está parada desde 2014". A Figura 2 ilustra os clusters de palavras descritos acima.

Estes resultados vão ao encontro ao estudo de Hunter e Sugiyama (2014) que afirmam que a inclusão social é consequência da possibilidade de as pessoas terem suas necessidades básicas atendidas de forma digna e que as políticas de bem-estar social podem estruturar os compromissos diários de maneira que aumentam a sensação de pertencimento do cidadão, podendo assim desencadear efeitos positivos. A última relação apresentada demonstra que o dinheiro público nas mãos de políticos corruptos promove a desigualdade social, a insegurança e a injustiça, como identificado nos relatos dos moradores de São Luís de Montes Belos (GO): “É um Brasil sem corrupção, um Brasil onde os filhos dos pobres possam ter acesso a um curso de medicina" e de Dois Vizinhos (PR): "Quero um Brasil mais fraterno com mais saúde, segurança, mais emprego, sem corrupção e com melhor distribuição de renda a todos os brasileiros".

As análises seguem para cada uma das cinco regiões do país (Norte, Nordeste, CentroOeste, Sudeste e Sul). Para isso, foram gerados clusters com o intuito de compreender o que os cidadãos de cada região esperam para o futuro do Brasil, que relacionam individualmente as quatro categorias: "cidadão", "democracia", "corrupção" e "justiça" considerando individualmente cada região do país. 
Figura 2 - Cluster de palavras e análise a nível nacional

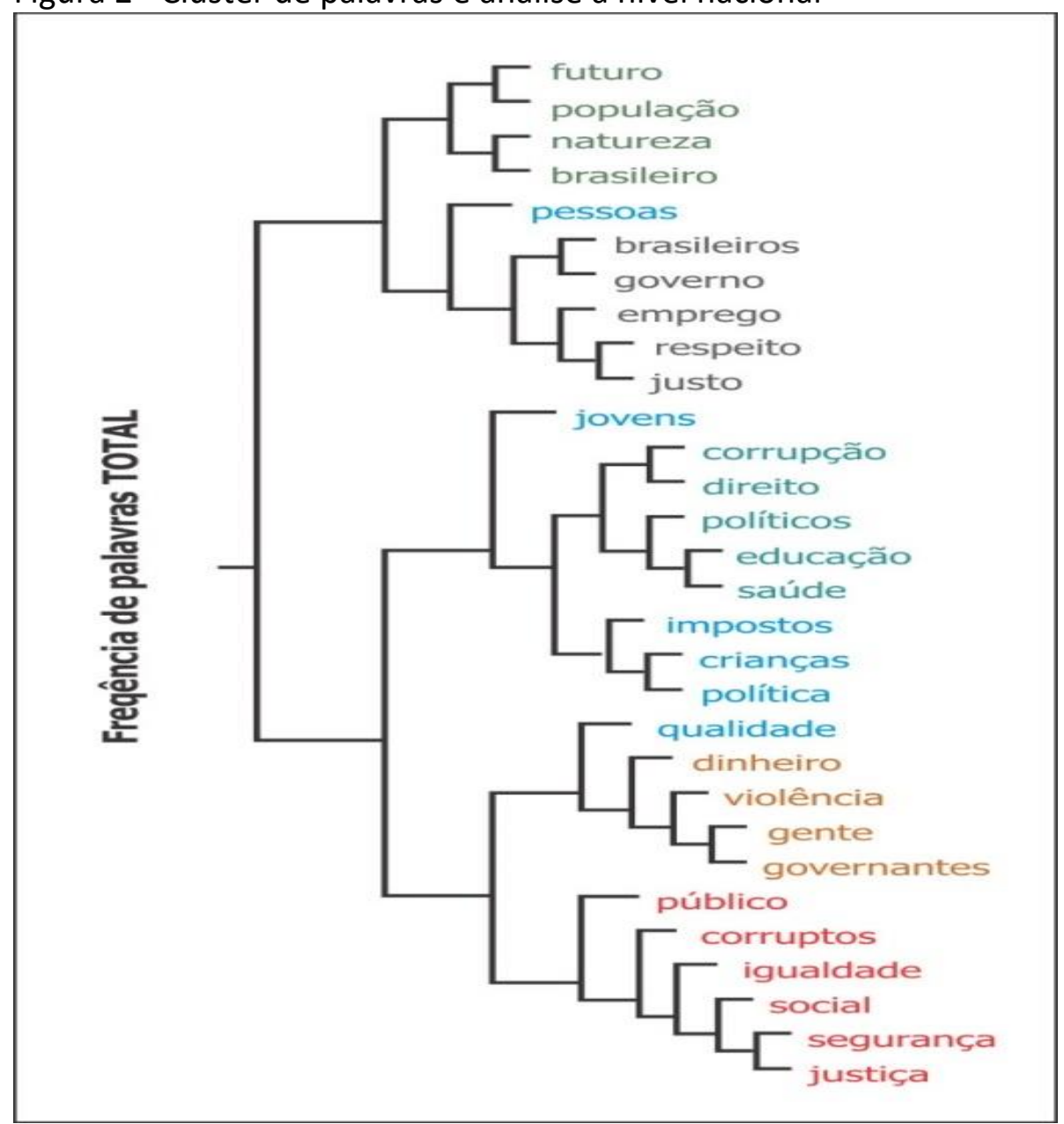

Fonte: Dados da pesquisa qualitativa (2018).

A região Sul, composta por três estados e 29.644 .948 habitantes (IBGE, 2010), apresentou a relação do termo "respeito" apenas ligando-o a "pessoas", sugerindo que o respeito deve partir do cidadão e não dos políticos, como relatou o morador de Treze de Maio (SC): “É preciso que as pessoas se respeitem mais, independente de opção sexual, opção religiosa, opção política ou classe econômica. Respeite as diferenças, você também" e o morador de Barracão (RS): “Quero um Brasil sem corrupção, com respeito e igualdade entre as pessoas para voltar a progredir".

Os termos "corrupção", "educação", "saúde", "políticos", "segurança" e "dinheiro público" também demonstram estar relacionados, como pode ser observado no depoimento do morador de Jandaia do Sul (PR): “É um Brasil sem corrupção, porque um Brasil sem corrupção vai sobrar dinheiro pra investir na educação, na moradia, na segurança, e principalmente, na saúde do nosso povo" e do participante de Vidal Ramos (SC): "É um Brasil sem corrupção, sem violência, e que os políticos se importem mais com nosso país do que com seus interesses próprios". Hoelscher (2015) afirma que embora a democracia eleitoral esteja firmemente estabelecida no 
Brasil, a corrupção política continua a ser um problema considerável, reconhecido também pelos cidadãos da região Sul do Brasil, como pode ser demonstrado nas falas dos participantes (Figura 3: $a$ e b).

Figura 3 - Relação entre a frequência e a ocorrência conjunta das palavras (a) e o agrupamento de palavras (b) nas respostas na região Sul do Brasil

(a)

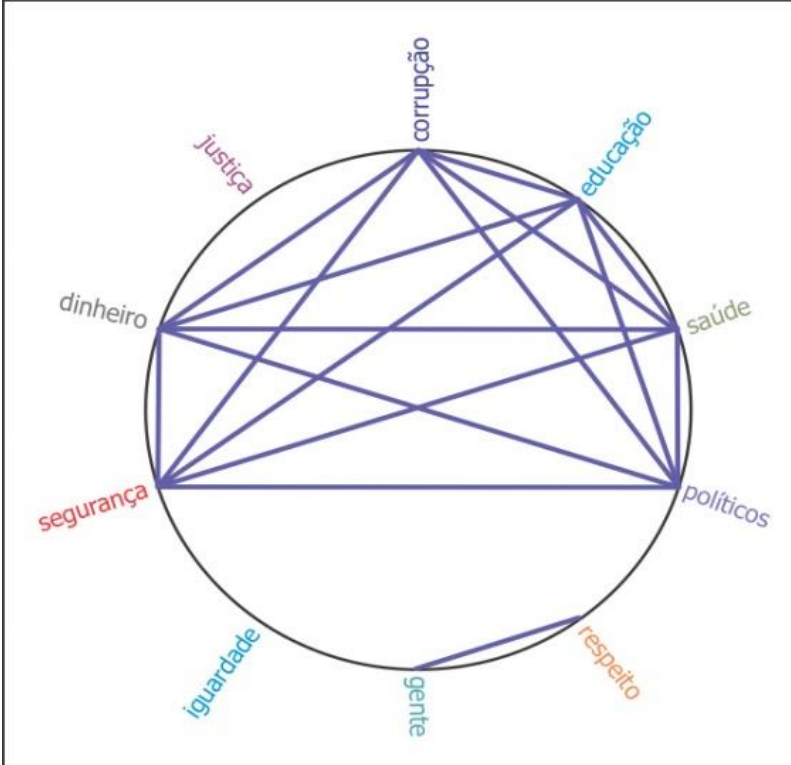

(b)

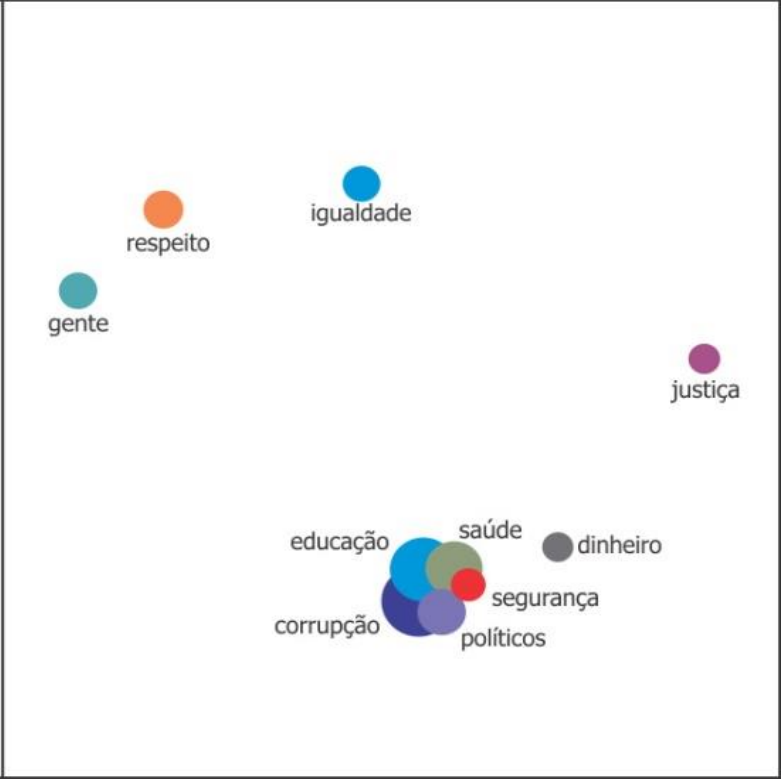

Fonte: Dados da pesquisa qualitativa (2018).

Na Figura 3 (b) ficam explícitos quatro grupos de palavras relacionados às ocorrências nas citações da amostra. O primeiro está relacionado às palavras "respeito", "pessoas" e "igualdade". O segundo inclui as palavras "políticos", "governantes" e "corrupção". O terceiro grupo representa a "saúde", a "educação" e a "segurança". Por fim, o quarto e último grupo, "futuro", com uma única ocorrência centralizada, mas próxima de "governantes", "corrupção" e "educação". A concentração de ocorrências é evidenciada pelos termos "educação", "saúde" e "corrupção", respectivamente.

O cluster representativo da Região Sudeste, composta por quatro estados e 86.949.714 habitantes (IBGE, 2010), apresentou uma relação semelhante ao cluster da região Sul, propondo que a população destas regiões possui a mesma forma de olhar a democracia e a política do país. O morador de Embu das Artes (SP) elucidou a necessidade de respeito entre as pessoas quando comentou: "É um país com mais coragem, amor e respeito. Coragem para gente continuar combatendo a corrupção, amor pra gente lembrar do que realmente importa e respeito para que ninguém mais seja discriminado pela cor, opção sexual ou religião" corroborado pela fala do participante de Pará de Minas (MG): "É onde o respeito prevaleça sobre o preconceito".

A relação, oriunda da confluência dos termos "corrupção", "saúde", "educação", 
"políticos e governantes", "dinheiro" e "segurança", é percebida na fala do morador de Itueta (MG): "Eu sonho com um Brasil melhor onde os governantes pensem em governar para o povo, não só para o próprio bolso como está acontecendo a tanto tempo. Estamos cansados de tanta corrupção e esperamos verdadeiramente mudanças" e do morador de Barra do Chapéu (SP): “É onde os políticos lutem contra a corrupção e torne a saúde e educação acessível para todos. Precisamos de fiscalização do dinheiro público das cidades pequenas".

As falas citam as mudanças na política que devem ocorrer para que o país consiga direcionar seus recursos para o atendimento das necessidades da população. Essa percepção tem consequências políticas importantes, a influência eleitoral de um grupo desfavorecido pode ser uma pré-condição para políticas voltadas ao seu bem-estar (ACEMOGLU; ROBINSON, 2000; 2006; FUJIWARA, 2015). A Figura 4 (a) e (b) apresentam os resultados da pesquisa na região Sudeste do Brasil .

Figura 4 - Relação entre a frequência e a ocorrência conjunta das palavras (a) e o agrupamento de palavras (b) nas respostas na região Sudeste do Brasil

(a)

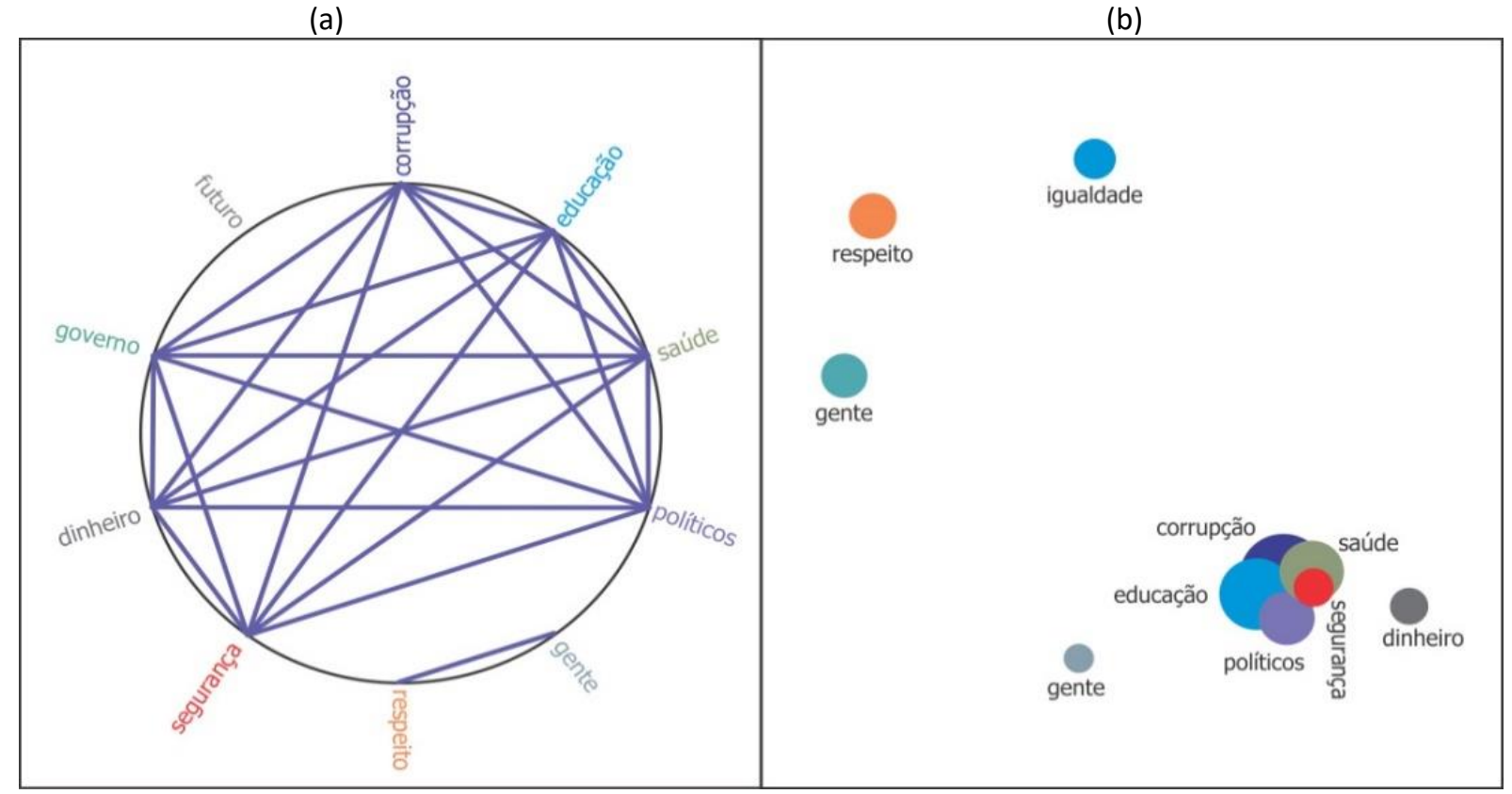

Fonte: Dados da pesquisa qualitativa (2018).

A Figura 4 (b) apresenta dois grupos de concentração de palavras relacionados às ocorrências de citações na amostra. O primeiro grupo está relacionado às palavras "saúde", "educação" e "segurança", semelhante aos resultados encontrados para a região Sul. O segundo grupo pode ser dividido em duas partes, uma delas à direita, incluindo os termos "corrupção", "políticos", "dinheiro" e "governantes", ligada aos termos "respeito" e "pessoas" pela palavra "futuro". A maior concentração de ocorrências de palavras é evidenciada pelos termos "educação", "saúde", "segurança" e "corrupção". 
O cluster para a região Centro-Oeste, composta por quatro estados e 15.875 .907 habitantes (IBGE, 2010), se assemelha aos clusters para as regiões anteriormente mencionadas, sul e sudeste, como citou o morador de Cidade Ocidental (GO): "Quero um Brasil com mais igualdade e respeito" e o participante de Campo Verde (MT): “Um Brasil onde cada pessoa seja consciente de seus atos. Um Brasil de identidade e consciência social".

A relação entre os termos "corrupção", "saúde", "educação", "políticos e governantes", "dinheiro" e "segurança", é fortalecida pelo depoimento do participante de Ouvidor (GO): "Queremos um Brasil mais seguro, educação de qualidade, salário digno para os trabalhadores, mais investimento na saúde, respeito às diferenças, zerar a corrupção" e pelo participante de Juara (MT): "É um Brasil com mais saúde, educação e segurança, com menos corrupção e com menos violência". O interesse eminente da população brasileira por educação se deve ao fato de que o preenchimento de uma cédula (voto) é uma tarefa trivial para cidadãos instruídos em países desenvolvidos, o que não acontece no Brasil, onde $23 \%$ dos adultos são incapazes de ler ou escrever uma simples nota (FUJIWARA, 2015). A Figura 5 (a) e (b) ilustra o cluster de palavras para os participantes da região Centro-Oeste.

Figura 5 - Relação entre a frequência e a ocorrência conjunta das palavras (a) e o agrupamento de palavras (b) nas respostas na região Centro-Oeste do Brasil

(a)

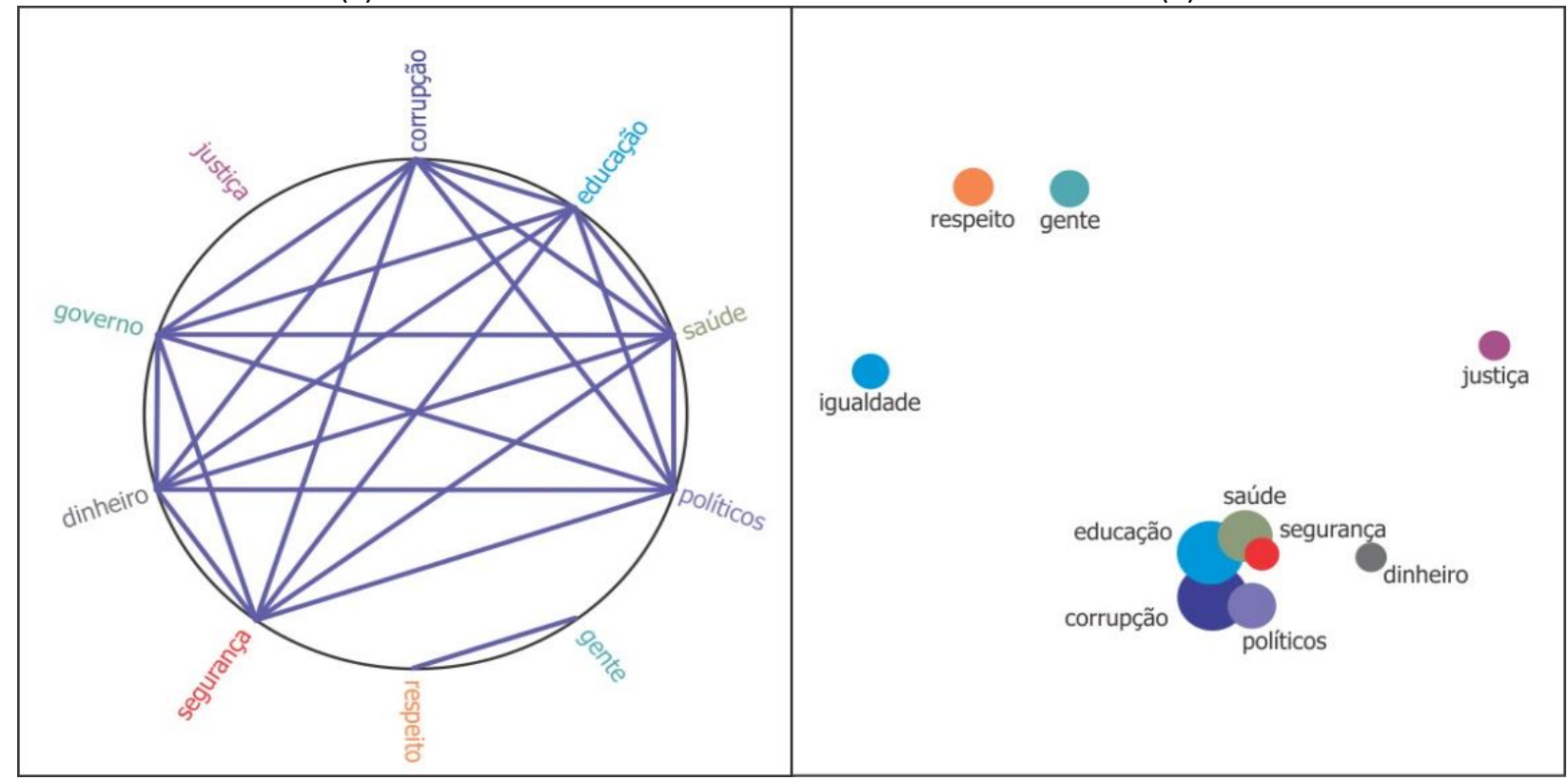

Fonte: Dados da pesquisa qualitativa (2018).

A Figura 5 (b) apresenta um resultado semelhante ao encontrado para a região Sul, resultando em quatro grupos de concentração de palavras conforme citações da amostra. A concentração de ocorrência de palavras é evidenciada, respectivamente, pela "educação", 
"saúde", "segurança" e "corrupção".

O cluster para a Região Nordeste, composta por nove estados e 57.254.159 habitantes (IBGE, 2010), apresenta as relações entre os termos "respeito" e "pessoas", bem como "corrupção", "educação", "saúde”, "políticos e governantes", "segurança” e "dinheiro público". O participante de Parnagua (PI) destaca o Brasil que quer para o futuro: "É um País civilizado onde as pessoas têm que ter mais responsabilidades, honestidade, respeito e amor ao próximo. A partir daí poderemos ter uma nação desenvolvida e melhor para se desenvolver", corroborado pelo participante de São Miguel (RN): “Um Brasil com mais respeito, amor e equidade. Enfim, tudo o que nos possibilita uma sociedade mais harmônica".

Segundo o morador de Milagres (BA) afirma: "Eu quero um Brasil sem corrupção, onde os governantes tenham méritos para administrar o dinheiro público, investindo na educação, saúde e segurança. Teremos um país seguro, uma nação saudável, educada e habilitada para atuar em várias áreas". Da mesma forma, o participante de Japaratuba (SE) destaca: "É um Brasil onde não corrupção, tenha mais educação, mais saúde, mais segurança e que os políticos tomem vergonha na cara e olhem a população que mais precisa". Nesse sentido, Terto Neto (2017) comenta que na sociedade brasileira, a desigualdade econômica e os níveis extremos de pobreza têm sido os aspectos mais visíveis da organização desigual e hierárquica das relações sociais como um todo, corroborando os achados do presente estudo. A Figura 6 (a) e (b) apresentam essas relações.

A Figura 6 (b) apresenta resultados semelhantes aos encontrados para as regiões Sul e Centro-Oeste (Figuras 3 (b) e 5 (b)), com quatro grupos de concentrações de palavras. A concentração de ocorrência de palavras é evidenciada pelos termos "educação", "saúde", "corrupção" e "segurança", de forma análoga aos achados para as regiões Sul e Centro-Oeste.

O cluster gerado com os resultados da pesquisa para a região Norte, composta por sete estados e 17.936.201 habitantes, possui similaridade com os demais, com exceção do termo "justo", ligado ao termo "dinheiro". Mesmo o termo "justo" aparecendo nas relações para as regiões Sul e Nordeste, ele não tinha ligação com os demais termos. Entretanto, para a região Norte, ao se ligar ao termo "dinheiro", a relação sugere que os brasileiros percebem justiça a partir do dinheiro investido para o bem púbico ou injustiça para o dinheiro desviado em função da corrupção. Essa relação pode ser entendida no relato do morador de Igarapé (PA): “É um Brasil fora da corrupção, um Brasil sem reeleição, que realmente os governantes que sejam colocados no poder venha fazer algo pelos pobres, algo pela população. Que venha criar leis que realmente venha beneficiar a população e não somente a eles mesmos" e pelo morador de Manacapuru 
(AM): "É um Brasil sem corrupção e que o dinheiro dos impostos volte com qualidade de vida para a população, tanto na saúde, na educação e na segurança".

Figura 6 - Relação entre a frequência e a ocorrência conjunta das palavras (a) e o agrupamento de palavras (b) nas respostas na região Nordeste do Brasil

(a)

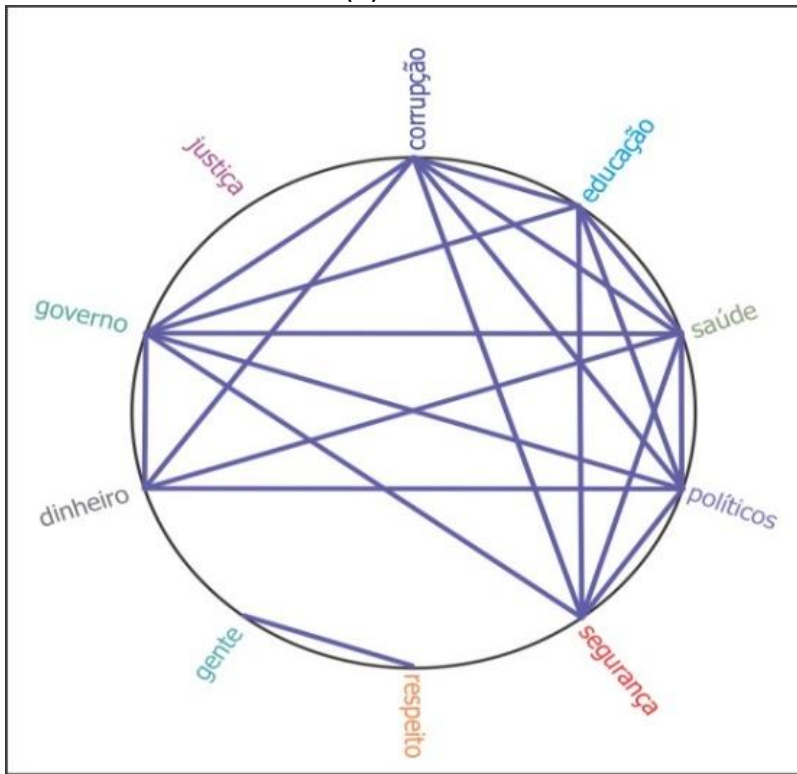

(b)

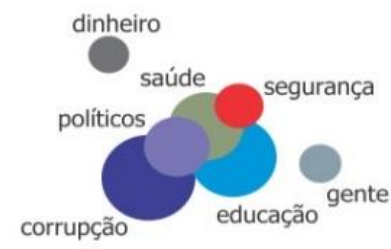

gente

Fonte: Dados da pesquisa qualitativa (2018).

Com relação aos termos "pessoas" e "respeito", o participante de Formoso do Araguaia (TO) argumentou: "Eu quero um Brasil com mais igualdade, mais respeito às comunidades indígenas, principalmente quando se trata na saúde indígena que está um caos". Complementando, o morador de Fátima (TO) deseja: "Quero um país onde o respeito fale mais alto que o preconceito. Um país com mais igualdade de direito e, principalmente, um país com mais oportunidades de emprego para nós jovens". Dessa forma, para a democracia insurgente brasileira, a justiça social é um princípio fundamental. É essa preocupação que estrutura o Estatuto da Cidade, em que o Estado aparece como a instituição encarregada de produzir a justiça social através de seus instrumentos de equalização (CALDEIRA; HOLSTON, 2015). A Figura 7 (a) e (b) apresenta essas relações.

A Figura 7 (b) apresenta o resultado para o agrupamento de palavras para a região Norte do Brasil, semelhante ao encontrado para as regiões Sul, Centro-Oeste e Nordeste, relacionados nas Figuras 3 (b), 5 (b) e 6 (b). A análise resultou em quatro grupos de concentração de palavras relacionados às ocorrências nas citações da amostra. Os grupos e palavras recorrentes foram os mesmos, exceto para a área relacionada à "saúde", "educação" e "segurança", onde aparece também o termo "qualidade". A concentração de ocorrência de palavras é evidenciada, 
respectivamente, pelos termos "educação", "saúde", "corrupção" e "segurança".

Figura 7 - Relação entre a frequência e a ocorrência conjunta das palavras (a) e o agrupamento de palavras (b) nas respostas na região Norte do Brasil

(a)

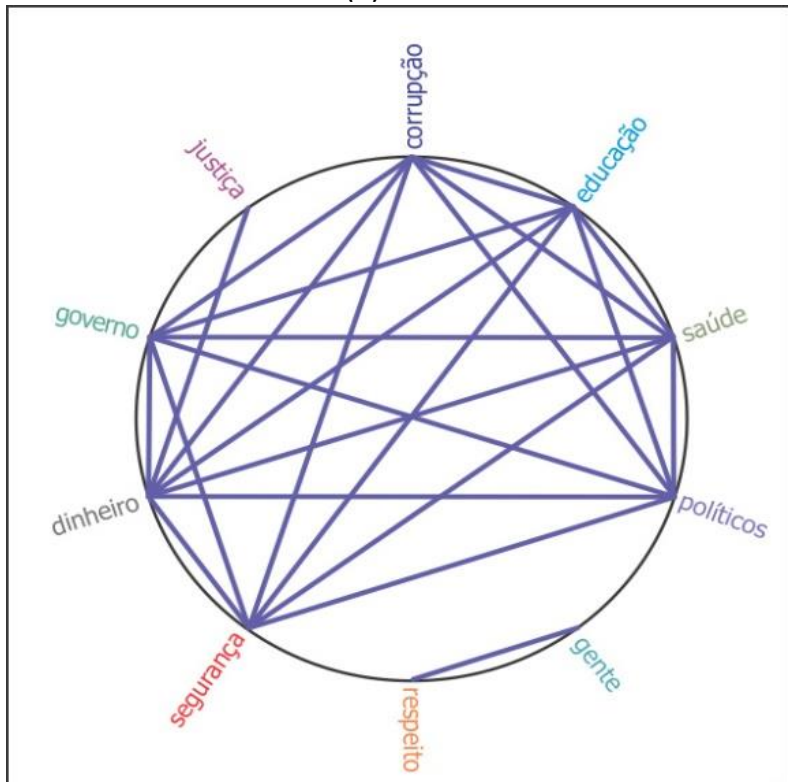

(b)

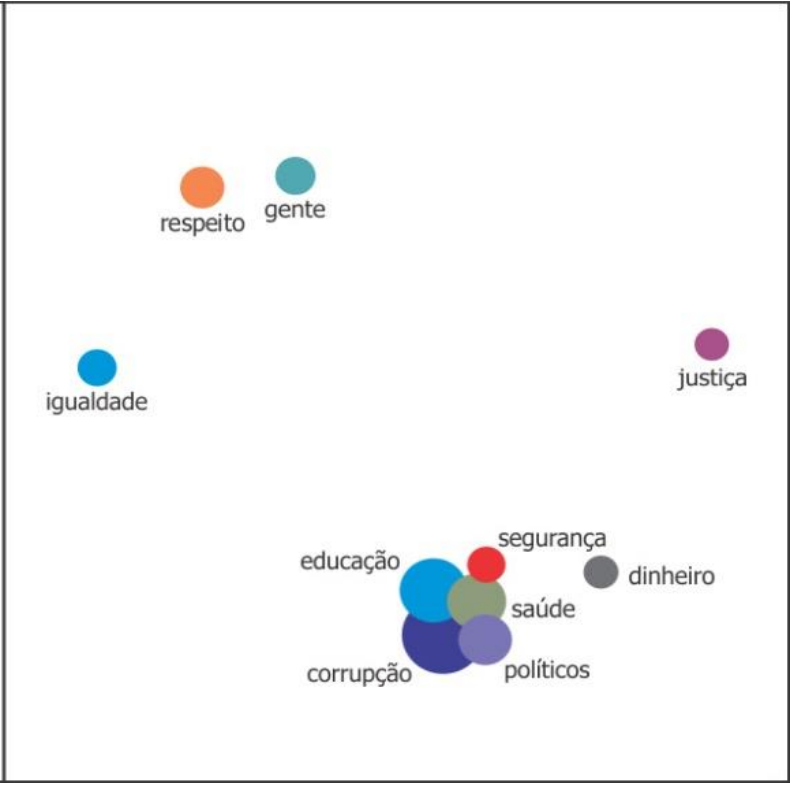

Fonte: Dados da pesquisa qualitativa (2018).

De forma geral, as demandas da população brasileira para o futuro do Brasil são as mesmas descritas na Constituição brasileira, em seu Artigo 6으, determina como direitos sociais do cidadão: a educação, a saúde, a alimentação, o trabalho, a moradia, o transporte, o lazer, a segurança, a previdência social, a proteção à maternidade e à infância e a assistência aos desamparados (BRASIL, 2015). No entanto, o que se observa são assistências ou serviços públicos não são prestados à população, que percebe tal deficiência.

Portanto, mesmo que a população tenha direito de tais serviços públicos, a corrupção se mostra como um elemento que dificulta esses serviços. Essa percepção da população quanto à corrupção e outras deficiências do país ocorrem de forma sistemática, identificada pelas trocas de governos e escândalos de corrupção. Desse modo, a participação da população, por meio da inovação social, poderá ser um caminho para iniciar e bloquear o desserviço público.

\section{Considerações Finais}

A necessidade de propor soluções aos riscos sociais prementes à sociedade brasileira motiva o interesse por inovações sociais por parte do poder público, da sociedade civil, das empresas privadas e dos próprios cidadãos. Diante disso, a emissora Globo, no seu papel de 
principal veículo de disseminação de informações, através de seus telejornais, oportuniza a população brasileira um espaço para a expressão de "Que Brasil você quer para o futuro"? contribuindo com uma inovação social, "chamando" a população a opinar sobre o futuro da nação, que atravessa um cenário de incertezas políticas e sociais. O conhecimento aplicado às necessidades sociais resulta em inovações sociais, por meio da participação e da cooperação dos agentes envolvidos, gera soluções novas e duradouras para grupos sociais, comunidades ou sociedades, principalmente em situações adversas, onde a escassez de recursos exige novas abordagens.

O ano de 2018, ano eleitoral no Brasil, em que são eleitos deputados federais e estaduais, senadores, governadores e o presidente que formarão o cenário político nacional pelos próximos quatro anos revela-se um período de constante discussão política, que oportuniza a reflexão sobre os rumos que o país deve tomar, atendendo aos anseios da população. Do processo eleitoral, evento democrático, espera-se que traga melhorias no desempenho do estado no atendimento as necessidades da população, regule os padrões de gastos públicos alocando recursos de maneira eficiente e justa e que contribua para a qualidade de vida da população.

Diante disto, este estudo teve o objetivo de descobrir o que a população brasileira deseja para o seu futuro por meio de uma análise de conteúdo a partir de vídeos apresentados pela emissora Globo. Por meio do material de pesquisa e análises realizadas, pode-se concluir que o que os brasileiros querem para o futuro do Brasil é um país que invista em educação, saúde, segurança pública e moradias dignas, principalmente para a parcela carente da população. Os brasileiros esperam que o dinheiro público, arrecadado pelo governo através do regime tributário nacional, seja investido em benefícios sociais, infraestrutura, educação e saúde, que traga melhorias para a qualidade de vida da população como um todo e não seja desviado por políticos corruptos. Os brasileiros desejam, para o futuro, que se tenha respeito com o dinheiro e patrimônio público e que os governantes busquem o bem comum em detrimento de seus interesses particulares.

Ao longo da pesquisa percebeu-se o sentimento de indignação da população brasileira diante dos casos de corrupção que assolam o país em todas as esferas. Além de exigir que os seus direitos constitucionais sejam atendidos, a população brasileira almeja o fim da corrupção no país, para o Brasil volte a ser um país respeitado no cenário internacional e atraia investimentos que possam contribuir para o seu desenvolvimento.

Outro achado de pesquisa se refere ao desejo das pessoas por uma sociedade mais justa 
em que o respeito entre as pessoas vença o preconceito de raça, classe social, religião, gênero e opção sexual. Por ser um país multicultural, sugere-se que estudos futuros sejam realizados no Brasil sobre temas como capital social de conexão social, motivando a confiança, a reciprocidade e a construção de redes que poderão contribuir para o desenvolvimento da cooperação entre as pessoas e das inovações sociais que o país tanto necessita.

A emissora Globo eximiu-se de divulgar como ocorreu o processo de seleção dos vídeos a serem exibidos nos seus telejornais, o que sugere um viés de seleção de dados por parte da emissora, que resulta em limitações aos resultados deste estudo. Estudos futuros poderiam comparar os achados expostos nas falas dos participantes com os indicadores de desempenho do país em termos de desenvolvimento humano, saúde, educação e qualidade de vida e com os Objetivos de Desenvolvimento Sustentável da Organização das Nações Unidas, posicionando o Brasil em parâmetros internacionais de desenvolvimento humano e social. Sugere-se que novos estudos sejam realizados de forma a detalhar mais as informações pra uma das regiões apresentadas neste estudo.

\section{Referências}

ABBAGNANO, Nicola. I Storia della filosofia: la filosofia antica, la patristica, la scolastica. UTET Libreria, 2017.

ACEMOGLU, Daron; ROBINSON, James A. Democratization or repression? European Economic Review, v. 44, n. 4-6, p. 683-693, 2000.

ACEMOGLU, Daron; ROBINSON, James A. Economic origins of dictatorship and democracy. Cambridge University Press, 2006.

BALÁN, Manuel. Surviving Corruption in Brazil: Lula's and Dilma's Success Despite Corruption Allegations, and Its Consequences. Journal of Politics in Latin America, v. 6, n. 3, p. 67-93, 2014.

BARDIN, Lourence. Análise de conteúdo. 3. ed. Lisboa: Edições, 70, 2011.

BENITES, A. Odebrecht, a gigante que ainda passa ilesa pela Operação Lava Jato. 2015. El País. Disponível em: http://brasil.elpais.com/brasil/2015/05/16/politica/1431731826_751292.html.

BIGNETTI, Luiz Paulo. As inovações sociais: uma incursão por ideias, tendências e focos de pesquisa. Ciências Sociais Unisinos, v. 47, n. 1, p. 3-14, 2011.

BOBBIO, N.; MATTEUCCI, N.; PASQUINO, G. Dicionário de política. Editora UnB, 2008.

BRASIL. [Constituição (1988)]. Constituição da República Federativa do Brasil de 1988. Brasília, DF: Presidência da República, [2016]. Disponível em:

http://www.planalto.gov.br/ccivil_03/constituicao/constituicaocompilado.htm. Acesso em: 24 jun. 2018.

BRASIL. Emenda Constitucional № 90, de 15 de Setembro De 2015. Dá nova redação ao art. 60 da Constituição Federal, para introduzir o transporte como direito social. Brasília, DF: 
Presidência da República, [2015]. Disponível em:

http://www.planalto.gov.br/ccivil_03/constituicao/emendas/emc/emc90.htm. Acesso em: 24 jun. 2018.

BEPA. Social Innovation: a decade of changes. BEPA Report, Luxembourg, Publications Office of the European Union, 2014.

CALDEIRA, Teresa; HOLSTON, James. Participatory urban planning in Brazil. Urban Studies, v. 52, n. 11, p. 2001-2017, 2015.

COLE, Matthew A.; ELLIOTT, Robert JR; FREDRIKSSON, Per G. Endogenous pollution havens: Does FDI influence environmental regulations? Scandinavian Journal of Economics, v. 108, n. 1, p. 157-178, 2006.

DA MATTA, Roberto. O que é o Brasil? Rocco, 2004.

DAHL, Robert A. On political equality. Yale University Press, 2006.

DAINIENE, Rasa; DAGILIENE, Lina. A TBL approach based theoretical framework for measuring social innovations. Procedia-Social and Behavioral Sciences, v. 213, p. 275-280, 2015.

DENZIN, Norman K.; LINCOLN, Yvonna S. Collecting and interpreting qualitative materials. Sage, 2008.

DOVAL, Gisela Pereyra; ACTIS, Esteban. The political and economic instability of Dilma Rousseff's second government in Brazil: between impeachment and the pragmatic turn. India Quarterly, v. 72, n. 2, p. 120-131, 2016.

FERNANDES, Carla Montuori. Rede Globo de Televisão: hegemonia e poder na trajetória do telejornalismo brasileiro. Punto Cero, v. 18, n. 27, p. 31-38, 2013.

FUJIWARA, Thomas. Voting technology, political responsiveness, and infant health: Evidence from Brazil. Econometrica, v. 83, n. 2, p. 423-464, 2015.

HAIR JR, J. F.; ANDERSON, R. E.; TATHAM, R. L.; BLACK, W. C. Análise multivariada de dados. Bookman, 2009.

HARAYAMA, Yuko; NITTA, Yoko. Introduction: Transforming innovation to address social challenges. Fostering innovation to address social Challenges, p. 11-17, 2011.

HOELSCHER, Kristian. Politics and social violence in developing democracies: Theory and evidence from Brazil. Political Geography, v. 44, p. 29-39, 2015.

HUNTER, Wendy; SUGIYAMA, Natasha Borges. Transforming subjects into citizens: Insights from Brazil's Bolsa Familia. Perspectives on Politics, v. 12, n. 4, p. 829-845, 2014.

IBGE. Instituto Brasileiro de Geografia e Estatística. Resultados. 2010. Disponível em: https://censo2010.ibge.gov.br/resultados.html. Acesso em: 12 jul. 2018.

LACERDA, Luiz Felipe Barboza; FERRARINI, Adriane Vieira. Inovação social ou compensação? Reflexões acerca das práticas corporativas. Polis Revista Latinoamericana, v. 12, n. 35, p. 1-16, 2013.

LYON, Vaughan. Carole Pateman, Participation and Democratic Theory. Cambridge: Cambridge University Press, 1970, pp. 122. Canadian Journal of Political Science/Revue canadienne de science politique, v. 4, n. 4, p. 583-584, 1971. 
MITRA, Arjyo. An ethical analysis of the 2014 FIFA World Cup in Brazil. Law \& Bus. Rev. Am., v. 21, p. 3, 2015.

MOULAERT, Frank et al. General introduction: the return of social innovation as a scientific concept and a social practice. The international handbook on social innovation: Collective action, social learning and transdisciplinary research, v. 1, p. 1-6, 2013.

MURRAY, Robin; MULGAN, Geoff; CAULIER-GRICE, Julie. How to Innovate: The tools for social innovation. Retrieved April, p. 2012, 2008. Disponível em:

http://youngfoundation.org/publications/how-toinnovate-the-tools-for-social-innovation/. Acesso em: 13 jun. 2018.

NEUMEIER, Stefan. Why do social innovations in rural development matter and should they be considered more seriously in rural development research? Proposal for a stronger focus on social innovations in rural development research. Sociologia ruralis, v. 52, n. 1, p. 48-69, 2012.

NUNES, Felipe; MELO, Carlos Ranulfo. Impeachment, political crisis and democracy in Brazil. Revista de Ciencia Política, v. 37, n. 2, p. 281-304, 2017.

OECD. Organization for Economic Co-Operation and Development. Forum on social innovations. 2017. Disponível em: http://www.oecd.org/cfe/leed/forum-social-innovations.htm. Acesso em: 13 jun. 2018.

POGREBINSCHI, Thamy; SAMUELS, David. The impact of participatory democracy: evidence from Brazil's national public policy conferences. Comparative Politics, v. 46, n. 3, p. 313-332, 2014.

POL, Eduardo; VILLE, Simon. Social innovation: Buzz word or enduring term? The Journal of Socioeconomics, v. 38, n. 6, p. 878-885, 2009.

REDE GLOBO. História Grupo Globo. 2017. Disponível em: http://historiagrupoglobo.globo.com/hgg/index.htm. Acesso em: 25 jul. 2018.

ROSE-ACKERMAN, Susan; PALIFKA, Bonnie J. Corruption and government: Causes, consequences, and reform. Cambridge University Press, 2016.

SCHUMPETER, J. A. The theory of economic developments: an inquiry into profits, capital, credit, interest, and the business cycle. Harvard University Press, 1961.

TERTO NETO, Ulisses. Democracy, social authoritarianism, and the human rights state theory: towards effective citizenship in Brazil. The International Journal of Human Rights, v. 21, n. 3, p. 289-305, 2017.

TOUCHTON, Michael; WAMPLER, Brian. Improving social well-being through new democratic institutions. Comparative Political Studies, v. 47, n. 10, p. 1442-1469, 2014.

VAILLANCOURT, Yves. Marges de manceuvre des acteurs locaux de développement social en contexte d'austérité. Centre de recherche sur les innovations sociales, 2017.

WEYLAND, Kurt. The Rise and Fall of President Collar and its Impact on Brazilian Democracy. Journal of Interamerican Studies and World Affairs, v. 35, n. 1, p. 1-38, 1993.

WEITZ-SHAPIRO, Rebecca; WINTERS, Matthew S. Os cidadãos podem discernir? Credibilidade da informação, sofisticação política e punição à corrupção no Brasil. The Journal of Politics, v. 79, n. 1, pág. 60-74, 2017. 